
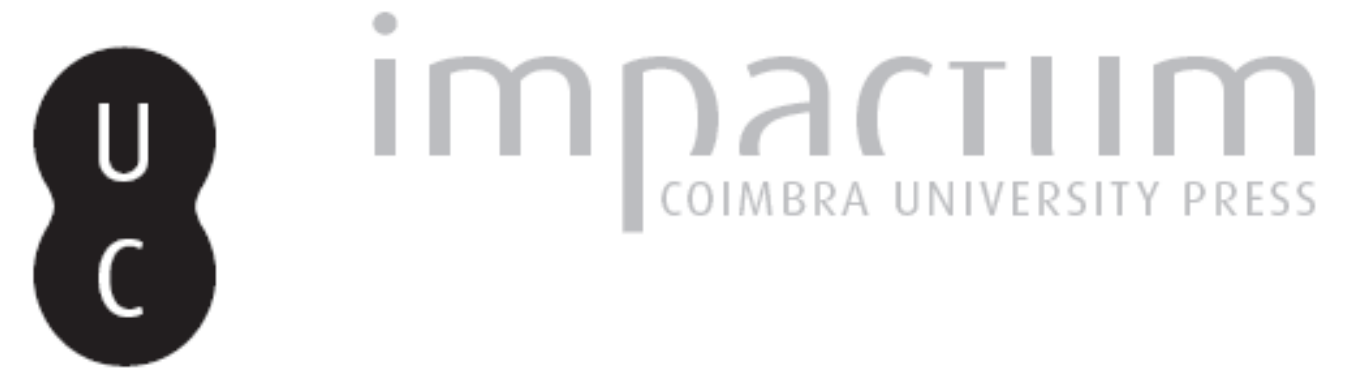

\title{
Reflexões sobre a epigrafia romana de Ossonoba
}

\section{Autor(es): D'Encarnação, José}

Publicado por: Imprensa da Universidade de Coimbra

URL persistente:

URl:http://hdl.handle.net/10316.2/45671

DOI:

DOI:https://dx.doi.org/10.14195/1647-8657_23_1

Accessed : $\quad$ 26-Apr-2023 12:24:37

A navegação consulta e descarregamento dos títulos inseridos nas Bibliotecas Digitais UC Digitalis, UC Pombalina e UC Impactum, pressupõem a aceitação plena e sem reservas dos Termos e Condições de Uso destas Bibliotecas Digitais, disponíveis em https://digitalis.uc.pt/pt-pt/termos.

Conforme exposto nos referidos Termos e Condições de Uso, o descarregamento de títulos de acesso restrito requer uma licença válida de autorização devendo o utilizador aceder ao(s) documento(s) a partir de um endereço de IP da instituição detentora da supramencionada licença.

Ao utilizador é apenas permitido o descarregamento para uso pessoal, pelo que o emprego do(s) título(s) descarregado(s) para outro fim, designadamente comercial, carece de autorização do respetivo autor ou editor da obra.

Na medida em que todas as obras da UC Digitalis se encontram protegidas pelo Código do Direito de Autor e Direitos Conexos e demais legislação aplicável, toda a cópia, parcial ou total, deste documento, nos casos em que é legalmente admitida, deverá conter ou fazer-se acompanhar por este aviso.

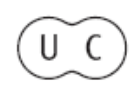


FACULDADE DE LETRAS

INSTITUTO DE ARQUEOLOGIA

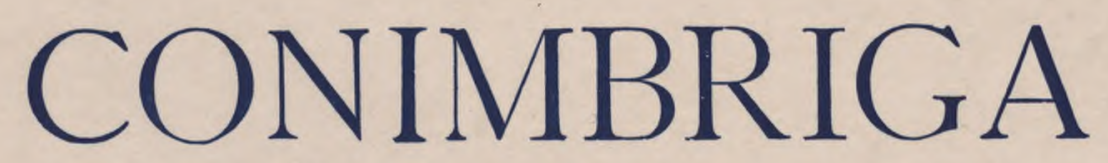

VOLUMEXXIII

UNIVERSIDADE DE COIMBRA

1984 
REFLEXÕES SOBRE A EPIGRAFIA DE OSSONOBA

«Conimbriga», XXIII (1984) p. 5-18

Resumo: O estudo conjunto das inscrições provenientes de Faro (antiga Ossonoba) e do seu termo permite desde já verificar a importância desta cidade durante toda a época romana.

Colonizada por elementos itálicos, a cidade teve grande desenvolvimento no Alto Império, atingindo o seu apogeu na $2 .^{\mathrm{a}}$ metade do séc. $m$.

RÉSUmé : L'étude de l'ensemble des inscriptions provenant de Faro (ancienne Ossonoba) et de son territoire nous permet de souligner, dès maintenant, l'importance de la ville pendant l'époque romaine.

Colonisée par des italiens, la ville s'est dévéloppée au Haut Empire. On peut situer son apogée à la deuxième moitié du $\mathrm{m}^{\mathrm{e}}$ siècle. 
(Página deixada propositadamente em branco) 


\section{REFLEXÕES SOBRE A EPIGRAFIA ROMANA DE OSSONOBA*}

Emílio Hübner incluiu no capítulo I do CIL II - Ossonoba inscrições provenientes não apenas do concelho de Faro mas também de todo o barlavento algarvio. Esta circunstância, acrescida à dispersão desses mesmos textos pelo suplemento e adendas do próprio GIL II, faz com que o leitor se possa facilmente perder quando pretende elaborar a carta de proveniências dos achados.

Obstou a esse inconveniente Maria Luisa Affonso dos Santos, na sua preciosa Arqueologia Monumental do Algarve $(=A R A)$. Contudo, não podia debruçar-se em pormenor sobre cada um dos inúmeros vestígios arqueológicos encontrados. $\mathrm{Na}$ esteira de seu bisavô, Estácio da Veiga, importava-lhe recolher o maior número possível de dados, pô-los à disposição do mundo científico, demorando-se aqui e além, mas nunca excedendo largamente a preocupação de tudo catalogar em vista a sínteses futuras. No que respeita à epigrafia, Maria Luisa coligiu informações bibliográficas, comparou leituras e decidiu-se pela que reputou mais convincente. Hoje, com base no seu trabalho, é-nos possível dispor de maior espírito crítico e tactear uma síntese doutra sorte muito difícil.

Síntese crítica que - embora provisória - se impõe. Primeiro, porque novos textos, novos métodos, novos conhecimentos se obtiveram. Depois, porque também na «Arqueologia Romana do Algarve» as epígrafes surgem dispersas, impossibilitando uma visão de conjunto - desvantagem que funciona igualmente como vanta-

* Comunicação apresentada ao IV Congresso Nacional de Arqueologia (Faro, 1980).

Conimbriga, 23 (1984), 5-18 
gem, pois nos fornece oportunas informações acerca do contexto arqueológico dos achados.

Mas os textos «velhos» - aqueles que de há muito se conhecem - importa revê-los também, num regresso à pedra ou à informação primeira em que Hübner se baseou nem sempre entendendo perfeitamente o nosso idioma.

E se o constante aparecimento de novos vestígios (arqueológicos e epigráficos) documentando outros focos de romanização, exigirá, no futuro, subdivisões geográficas ao capítulo «Ossonoba» do CIL II - Faro e o seu termo oferecem, desde já, importante campo de retlexão, com os trinta e seis textos que inventariámos (e outros haverá).

Situa-se Ossonoba na proximidade de três importantes locais: Milreu (Estói), Quinta do Marim (Olhão) e Balsa.

A riqueza arquitectónica das ruínas romanas de Milreu, o aparecimento aí de estátuas imperiais - sugerem, cada vez mais, a certeza de que estaremos perante uma propriedade do Estado, quiçá do governador provincial que nela residiria temporariamente. Foi talvez numa dessas permanências que o governador Aurelius Ursinus «assinou» um texto oficial do séc. iv (CIL II 5140), cujo teor se desconhece mas que devia ser importante (Apêndice documental, texto 3).

A Quinta do Marim, com cerca de duas dezenas de monumentos funerários artisticamente conseguidos, memorando escravos de onomástica a denotar bons conhecimentos da cultura grego-romana (Amimetus, Chrysantus, Diodor a, Eros, Patroclus, Troilus, Tyche) — surge como propriedade de ricos senhores.

Por fim, Balsa, nas proximidades de Tavira, com uma notável epigrafia monumental (CIL II 5165 e 5166) e inscrições honoríficas do maior interesse (CIL II 5161 e 5162) — apresenta-se habitada por uma burguesia empreendedora, cuja actividade e renome não ficam por mãos alheias. $E$ se encontramos perto de Beja um incola Balsensis (CIL II 105), é-nos grato dar a conhecer uma epígrafe inédita de Faro, por nós identificada no museu desta cidade (n. $\left.{ }^{\circ} 30\right)$, que demonstra bem as relações entre Ossonoba e Balsa (texto 7): inscrito na tribo Quirina, que é a de Balsa (CIL II 5264), L. Ânio Novato pertence provavelmente à mesma gens daquele Primitivus, que, por ter sido elevado às honras do 
sevirato, em Balsa organizou combates de barcas e gladiadores, distribuindo benesses aos cidadãos (GIL II 13 = ILER 449); a ela pertencerá também C. Annius Romulus, cujo epitáfio (CIL 113 = ILER 3216) se encontrou na Fuzeta.

Ossónoba não era, pois, uma cidade qualquer. A sua dinâmica burguesia rica envolvia-se nos problemas administrativos do governo central e local, e procurava a notoriedade através de importantes construções públicas. Activo porto de mar, Faro viveria do comércio e por ele também se escoariam decerto produtos mineiros do interior, como parece ter demonstrado o aparecimento dum lingote com a marca PROC(urator) [OSJSONOBANSIS, datável da 2. ${ }^{a}$ metade do séc. $\mathrm{n}$ ou $1 .^{\circ}$ quartel do $\mathrm{m}$ (M. EuzenNat, 1968-1970, p. 89-98).

As relações com o poder central - reflexo certamente também do interesse deste pela região - estão patentes nas dedicatórias feitas ex decreto ordinis a Valeriano, em 254 ou 255 [Texto 1), e a Aureliano, em 274 [Texto 2), pela Respublica Ossonobensis (ou Ossonobensium), que em ambas se declara devota numini maiestatique eius (CIL 111 = ILER 1186 e EE IX 1 = ILER 1196).

Perdeu-se o monumento em honra de Valeriano. Contudo, apesar de ter sido primeiramente referido por André de Resende; apesar das analogias flagrantes com a epígrafe a Aureliano; apesar de faltar a indicação do número do consulado - o texto deve ser tido como autêntico: viu-o e releu-o Frei Vicente Salgado; as analogias explicam-se pela escassa diferença cronológica; as anomalias textuais são comuns na epigrafia dos imperadores a partir de 250 .

A dedicatória a Aureliano está no Museu de Faro. Pedestal de calcário praticamente intacto, foi achado - como o anterior já reaproveitado, de forma que se desconhece o contexto arqueológico inicial. Mas, numa cidade, o lugar das estátuas imperiais é no forum. Conhecem-se poucas dedicatórias peninsulares a Aureliano. Tivemos ocasião de reconstituir uma outra em Santiago do Cacém, na esteira da hipótese lançada por D. Fernando de Almeida (1964, p. 19): datável muito provavelmente de 275, desconhece-se o seu dedicante, mas tudo leva a crer que serão os habitantes de Miróbriga.

$\mathrm{Na}$ altura em que os imperadores assumindo o poder se revestem duma aura mística, tentando reerguer a unidade dum 
império prestes a sossobrar; numa época de declínio do culto imperial, em que os dedicantes são geralmente as entidades administrativas, num estendal de fórmulas estereotipadas que não brotam da fé (ÉTIENNE 1958, p. 501-504), — seria interessante descortinarmos o motivo real destas homenagens. Uma certeza resta, contudo - elas demonstram em Ossónoba uma atenção aos problemas do Império, uma afirmação de lealdade a Roma, patenteando ao mesmo tempo excelente funcionamento das instituições tradicionais: o monumento é erigido por decreto dos decuriões - ex decreto ordinis-, facto que justamente se realça pela utilização dessa fórmula por extenso.

A nível provincial, a importância de Ossónoba está documentada por uma epígrafe pouco conhecida - e até ao momento deficientemente interpretada - mandada lavrar pela civitas Ossonobensis (ou Ossonobensium) a um dos seus patronos: Marco Cornélio Persa, filho de Quinto, da tribo Galéria, flâmine da província da Lusitânia (Texto 4). E se o cognome Persa, de mui rara ocorrência, pode interessar-nos do ponto de vista da onomástica e das relações culturais; se a grafia Lysitani(ae) importa no domínio da Linguística - é, contudo, a designação civitas que primeiramente nos desperta a atenção. Pela paleografia e pela indicação da tribo, o monumento situa-se no séc. i ou, quando muito na 1. ${ }^{a}$ metade do II. Ora, nas dedicatórias imperiais a designação é outra: respublica. À primeira vista, somos levados a pensar em designações oficiais, indicativas dum estatuto administrativo determinado. Tal não acontece, porém; respublica e civitas parecem ter o sentido vago de «conjunto de cidadãos» sem lhes precisar a situação jurídico-administrativa, aplicando-se tanto a um município como a uma colónia. Assim, Gades é designada municipium Augustum Gaditanum (CIL II 1313) e respublica Gaditana (CIL II 1731); aos habitantes de Hispalis aplicam-se as expressões civitas Romulensium (CIL II 1180), colonia Hispalensium (CIL II 1193) e respublica Hispalensis (CIL II 1171). Note-se, todavia, que num pedestal erguido em Cástulo ao imperador Valeriano, em 257 ou 258, o «dedicante» se designa Respublica Castulonensium, declarando igualmente a sua devoção ao génio e majestade imperiais (Contreras 1966) como em Faro. Por conseguinte, dispomos aqui de dados concretos: a palavra civitas utilizada na homenagem 
a um particular, sem a explicitada intervenção dos poderes municipais; respublica utilizada mais tarde, na homenagem ao imperador, com declarada intervenção da ordo decurionum, mencionada embora genericamente sem referência a magistrados. Será esta a regra? Para o confirmar, haveria que coligir, depois de convenientemente datados, outros textos peninsulares (e não só) documentando essa dupla designação ao mesmo aglomerado populacional, de forma a detectar traços comuns.

Mas falemos da importância do monumento em si. Embora liso na parte superior, ele pode considerar-se um pedestal, atendendo à lei do concilium da Narbonense, citada por R. Étienne (1958, p. 122), segundo a qual, acabadas as suas funções, os flâmines deviam ser honrados com estátuas. Patrono da civitas, cidadão romano inscrito na tribo Galéria, de Faro, Persa deverá incluir-se entre os sete sacerdotes imperiais da Lusitânia referidos por R. Étienne (1958, p. 122-126), com uma origem geográfica precisa. Ossónoba figurará, pois, na lista das cidades que elegem representantes seus à assembleia provincial a fim de participarem na eleição do flâmine da província. O que demonstra a sua inequívoca vitalidade.

Vitalidade que tem evidente contrapartida monumental: a inscrição CIL II 2 = 5133 refere a oferta — dum lugar público? feita por Marco Cornélio Eridano e Gaio Júnio Recepto, aquando da sua elevação ao sevirato (Texto 8). Trata-se dum monumento em mármore com a forma de lintel para figurar sobre a porta dum edifício; a inscrição está, como convém, dentro duma tabula ansata (como a do mosaico de que falaremos adiante); na parte de trás há um ressalto para facilitar a fixação; em baixo, dois buracos de cada lado para os gonzos. Que edifício seria esse?

Contudo, não fica por aqui a epigrafia monumental de Faro. Uma extensa lista de libertos - igualmente não muito divulgada e passível de correcções de leitura (Texto 5) - datável paleograficamente dos finais do séc. $\mathrm{n}$, informa da constituição de, certamente, uma comissão de homenagem ou para erecção dum monumento. Além dos nomes (e a lista não é exaustiva), temos a parte final, muito maltratada, onde se distingue o genitivo ossonobensivm : aí se encontraria, decerto, a especificação do «colégio» cujos membros vêm citados antes: este genitivo sugere-nos um outro - Balsen- 
sium - que figura também após a lista dos promotores de outra homenagem, em Balsa (CIL II 4989).

Outras quatro pessoas - C. Calpurnius (...), G. Vibius Quintilianus, L. Attius (...) e M. Verrius Geminus - se uniram para doarem à população ossonobense o imponente mosaico do Oceano, encontrado nos começos de 1976. E se apenas a continuação de escavações e o estudo das dimensões do mosaico e da sua integração espacial permitirão avançar hipóteses acerca do edifício, certamente mais público do que privado, em cujo vestíbulo o monumento estava inserido - é, contudo, de salientar a sua imponência, a excelência do Latim e, sobretudo, uma curiosidade que as operações de restauro deram a conhecer: segundo amável comunicação da Sr. ${ }^{a}$ Dr. ${ }^{a}$ Adília Alarcão, do Museu Monográfico de Conimbriga (entidade que teve a seu cargo todo o trabalho de levantamento, restauro e consolidação do monumento), nas tesselas foram detectados vestígios de tinta vermelha, o que veio mostrar, pela primeira vez, como se processava a execução dum mosaico: havia efectivamente um esboço prévio pintado na argamassa.

Uma análise, ainda que rápida, da onomástica documentada nestas e noutras epígrafes ossonobenses, não deixa de ser elucidativa. Falámos de M. Cornélio Persa, flâmine, de Marco Gornélio Eridano, sevir. Poderão pertencer à mesma família: imaginaríamos, com prazer, em Ossónoba, uma família de M. Cornelii, burgueses municipais, que libertaria Eridano. Mas, neste aspecto, a lista dos libertos (Texto 5) é mais elucidativa - eles estão relacionados com algumas das famílias mais importantes documentadas, ao tempo dos Romanos, em Faro e arredores: Acilia, Aelia, Aemilia, Annia, Licinia (três L. Licinii). Toda uma onomástica perfeitamente latina, como o é aliás a dos doadores do mosaico, sem o menor traço de indigenato. Aqui estão representados os Calpurnii (gens que ocupa o $20 .^{\circ}$ lugar na lista dos gentilicios mais frequentes no conjunto do CIL II: 66 exemplos, 0,97\%, segundo R. C. Knapp 1978, p. 221); os T. Manlii (um T. Manlius Lacon - CIL II 12 = ILER 3218), tão bem atestados em Balsa (CIL II $5161=$ ILER 1525, CIL II $5162=$ ILER 5264); os Vibii, que na Peninsula se fixaram com maior densidade na bacia do Guadalquivir... 
População dinâmica, população latina, população culta, cuja epigrafia surge bem acompanhada por uma arte cosmopolita: mostram-no o mosaico do Oceano, que, ladeado pelos Ventos, as quatro direcções, assume aqui um carácter universal, de Mar Exterior (como nos comunicou a Dr. ${ }^{a}$ Maria Manuel de Almeida); o elegante vaso de libações gravado na não menos elegante ara, existente no Museu de Faro, dedicada por um outro Calpurnius - L. Calpurnius Teodorus - a sua mulher, Caturica Prima (CIL II 4, leitura corrigida); a graciosa decoração — pátera, vaso de libações e crescente - do cipo de Caecilia Marina, ossonobense (GIL II $5142=$ ILER 5385); os preciosos ornatos dos epitáfios da Quinta do Marim, nomeadamente da cupa de Patrícia (CIL II 5143 = ILER 3377); e, sobretudo, o lindíssimo capitel de ara funerária, ainda inédito, com profusa decoração simbólica nas suas quatro faces (Foto 6).

Ossónoba detém, desta sorte, no contexto da romanização do sul do território actualmente português, um papel bem relevante.

Esperando que a Arqueologia o venha confirmar, a Epigrafia demonstra-o já cabalmente - colonizada por elementos itálicos, a cidade conheceu grande desenvolvimento no Alto Império, atingindo o seu apogeu na segunda metade do séc. $m$ da nossa era.

\section{APÊNDICE D0CU3IENTAL}

\section{Inscrição a Valeriano}

IMP(eratori) . CAES( $\left.\operatorname{ar}_{i}\right)$. P(ublio) . LI/CINIO . VALERIANO . $\mathrm{P}(\mathrm{m})$. F(elici) . $\operatorname{AVG}\left(\wedge^{\text {sto }}\right) . \operatorname{PONT}\left(i / \mathrm{c}_{i}\right) / \operatorname{MAX}(i \mathrm{mo})$. $\mathrm{P}$ (atri). $\mathrm{P}$ (atriae). TR (ibunicia). POT \{estate). Ill (tertia) $/ 5$ CO(ri)§(uli). RES . P(ublica) . OSSON(obensium) / EX . DECRETO . ORD(inis) I DEVOTA . NVMINI / MAIESTATIQ(we) . EIVS / $\mathrm{D}$ (edit). $\mathrm{D}$ (edicavitque). 
Ao imperador César Públio Licinio Valeriano Pio Félix Augusto, pontífice máximo, pai da Pátria, no seu $3 .^{\circ}$ poder tribunicio, cônsul - a República dos Ossonobenses, por decreto da ordem (dos decuriões), ofereceu e dedicou, por devoção ao seu génio e majestade.

Resende I, p. 240. SAlgado, p. 90-91 e 149-150. CIL II $1=$ ILS $534=$ ILER 1186. ÉTIENNE 1958, p. 311 e 507 (referências). ARA I 1971, p. 169-170.

\section{Inscrição a Aureliano (Foto 1)}

IMP(eratori) (hedera) CAES(aní) / L(ucio) (hedera) DOMITIO / AVRELIANO / PIO (hedera) FEL( ¿cic) (hedera) AVG(usto) /5 P(ontifici) (hedera) $\mathrm{M}$ (aximo) (hedera) Tribunicia) (hedera) $\mathrm{P}$ (otestate) (hedera) P (atri) (hedera) P (atriae) (hedera) / II (iterum) (hedera) $\mathrm{CO}(/ \mathrm{I}) \mathrm{S}\left(\mathrm{HZ}_{i}\right)$ (hedera) PROC(onsuli) / R(es) (hedera) $\mathrm{P}$ (ublica) (hedera) OSSOmB(ensium) / EX DECRETO / ORDIN(fs) / 10 D(evota) (hedera) N (umini) (hedera) M(aiestatique) (hedera) EIVS / D (edit) (hedera) D(edicavitque) (hedera).

Ao imperador César Lúcio Domicio Aureliano Pio Félix Augusto, pontífice máximo, no seu poder tribunicio, pai da Pátria, cônsul pela segunda vez, procônsul — a República dos Ossonobenses, por decreto da ordem (dos decuriões), ofereceu e dedicou, por devoção ao seu génio e majestade.

VASCONCELOS 1900, p. 43-44 = EE IX 1 - AE 1897, n. $49=$ $=\mathrm{AE} 1900$, n. 31. Номо 1904, p. 353 (citado por SotgIU, 1961, p. 21). ILER 1196. ARA I 1971, p. 170-171.

3. Inscrição dum governador da Lusitânia (Foto 2)

[...] / AV [...] / AVR(elius) VRSINVS V(¿r) P(erfectissimus) PR(aeses) / PROVINCE) . LVSITANI(ae).

Conimbriga, 23 (1984), 5-18 
... Aurélio Ursino, varão perfeitíssimo, governador da província da Lusitânia.

FiGUEiREno 1887, p. 47-48, 93-94. CIL II 5140. BaliL 1965, p. 56 (referência). Chastagnol 1965, p. 281 (referência). Plre 1971, p. 987. ARA I 1971, p. 171-2. ILER 1245-6.

4. Inscrição dum flâmine provincial (Foto 3)

M (arco)CORNELIO / Q (uinti)F GAL(eria tribu) PERSAE / FLAMINI / PROVINCIAE LYSITANI(ae) [sic] /5 CIVITAS OSSONOB(eresium) / PATRONO.

A Marco Cornélio Persa, fdho de Quinto, da tribo Galéria, flâmine da província da Lusitânia — a cidade dos Ossonobenses ao (seu) patrono.

Franco $1940^{2}=A R A$ I, 1971, p. 172-3.

5. Lista de libertos (Fotos 4 e 5)

1. a coluna:

Q (uintus)IVNIVS AVITIANVS / L AEMILIVS THEMISON / L( ucius) PVBLÍCIVS VRBANVS / L CAÉCILIVS PLOCAMVS / L(ucius) LICINIVS FRVCTVS / L CAECILIVS NYMPHODOTVS / MARIVS MAXVMVS / $\mathrm{M}$ FABIVS MYRTILVS / L (ucius)CAECILIVS SYMPHORVS /10 M(arcns) IVLIVS AVITIANVS / [...] GEMINIVS CALLISTVS $/ / / /[\ldots ?] /[\ldots]$ NIVS / $[\ldots]$ NTVS / $[\ldots]$ /5 [...] [OSJSONOBEN$\operatorname{sivM} /[\ldots] /[\ldots] /[\ldots]$.

2. a coluna:

L \{ucius)LIVIVS MARTIALIS / L LICINIVS CALVVS / L (ucius)ANNIVS LAPILLIANVS / L(ucius) CAECILIVS LIBERALIS / L (ucius)HERENNIVS COSCONIVS / L(ucius) AELIVS SVPERSTES / CN(aews) ACILIVS RVFVS / Q(uintus) IVNIVS 
CHRYSANTHVS / M (arcus) CAECILI VS VRBANVS /10 h(ucius) LICINIVS OPILIO.

Quinto Júnio Avitiano, Lúcio Emílio Temisão, Lúcio Publicio Urbano, Lúcio Cecilio Plocamo, Lúcio Licinio Fruto, Lúcio Cecilio Ninfodoto, Mário Máximo, Marcos Fábio Mirtilo, Lúcio Cecilio Sinforo, Marcos Júlio Avitiano, (...) Gemínio Calisto (...) dos habitantes de Ossónoba.

Lúcio Lívio Marcial, Lúcio Licinio Calvo, Lúcio Ânio Lapiliano, Lúcio Cecilio Liberal, Lúcio Herénio Coscónio, Lúcio Élio Superstes, Gneu Acilio Rufo, Quinto Júnio Crisanto, Marcos Cecilio Urbano, Lúcio Licinio Opilião.

FrANCO $1940^{1}=A R A$ I 1971 , p. 173-5.

\section{Mosaico}

C(aius) . CAL.PVR.NI.VS [...] NVS . ET . G(aius) VI . BI.VS . QVINTI./LI.A.NVS . ET . L(ucius) / AT.TI[VS ? ...] S . ET . $\mathrm{M}$ (arcus) VER.RIVS CE.MI.NVS . / SOL[VM] TES.SEL.LAS [F(aciendum) CV.RA.RVNJT ET . DONA. [RVN].T .

Gaio Calpúrnio ... e Gaio Vibio Quintiliano e Lúcio Átio (?) ... e Marco Vérrio Gémino ... (mandaram fazer) e deram o solo e as tesselas.

\section{Alarcão 1980.}

7. Dedicatória a Novato

L(ucio) ANNIO / QVIR(ma tribu) / NOVATO [...]

A Lúcio Ânio Novato, da tribo Quirina... 
8. Inscrição de dois seviros

M(arcus) . GORNELIVS . ERIDANVS . ET G(aius) . IVNIVS RECEPTVS / OB . HONOREM . IIIIIVIR (,seviratus) . D(e) . S (ua) . P \{ecunia) . D (ono) . D [ederunt) .

Marco Cornélio Eridano e Gaio Júnio Recepto, em honra do (seu) sevirato, ofereceram a expensas suas.

CIL II 2 e 5133. Vasconcelos 1913, p. 324. ILER 1513. Étienne 1958, p. 254 e 261. ARA I 1971, p. 175-176. Mangas 1971, p. 311 (referência).

\section{BIBLIOGRAFIA}

$\mathrm{AE}=$ VAnnée Epigraphique, Paris.

Almeida (D. Fernando de), Ruínas de Mirobriga dos Célticos (Santiago do Cacém), Setúbal 1964.

Alarcão (Adília) et alii, O Mosaico do Oceano, de Faro, "Anais do Município de Faro», X, 1980, p. 219-232.

$A R A=$ Santos (Maria Luisa Estácio da Veiga Affonso dos), Arqueologia Romana do Algarve, Lisboa, I, 1971, II, 1972.

B alil (A.), Los legados de la Lusitania, «Gonimbriga», IV, 1965, p. 43-57.

Chastagnol (André), Les Espagnols dans Varistocratie gouvernementale à Vépoque de Théodose, «Les Empereurs Romains d'Espagne», Paris, 1969, p. 269-292.

CIL II = Hü B Ner (Emílio), Corpus Inscritpionum Latinarum II, Berlim, 1869, Suplemento 1892.

Contreras (R.), Cástulo y el emperador Valeriano, «Oretania», XXIII-XXIV, 1966, p. 246.

EE IX = Dessau (H.), Additamenta nova ad Corporis volumen II, «Ephemeris Epigraphica», IX, 1903, p. 12-185.

Étienne (Robert), Le Culte Impérial dans la Péninsule Ibérique d'Auguste à Dioclétien, Paris, 1958, reimp. 1974.

Euzennat (M.), Lingots espagnols retrouvés en mer, «Études Classiques», III, 1968-1970, p. 83-98, 89-98.

Figueiredo (B. de), Epigrafia, «Revista Archeologica e Historica», I, 1887, p. 47-48, 93-94.

Franco (Mário Lyster), Uma inscrição inédita de Ossonoba, separata de «Costa de Oiro», 64 (Abril-Maio 1940);

_._, Outra inscrição inédita de Ossonoba, Beja, 1940.

номо (L.), Essai sur le règne de Vempereur Aurélien (270-275), Paris, 1904.

Gonimbriga, 23 (1984), 5-18 
ILER = Vives (José), Inscripciones Latinas de la España Romana, Barcelona, 1971, índices 1972.

KNAPP (R. C.), The origins of provincial prosopography in the west, «Ancient Society», IX, 1978, p. 187-222.

PLRE = Prosopography Latin Roman Empire, Oxford, 1971.

RESENDE (André de), De antiquitatibus Lusitaniae..., Coimbra, 1790, 2 tomos (reedição).

SALGado (Frei Vicente), Memorias ecclesiasticas do Reino do Algarve, Lisboa, 1786.

Sotgiu (Giovanna), Studi sulVEpigrafia de Aureliano, Palumbo 1961.

Vasconcelos (J. Leite de), Inscripção romana de Ossonoba, «O Archeologo Português» V 1900, p. 43-44;

----- Religiões da Lusitânia... Ill, Lisboa 1913. 


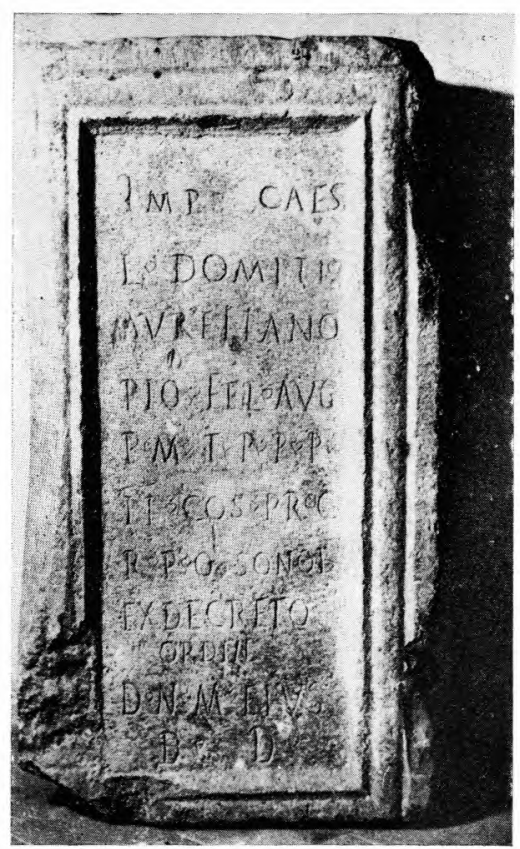

1

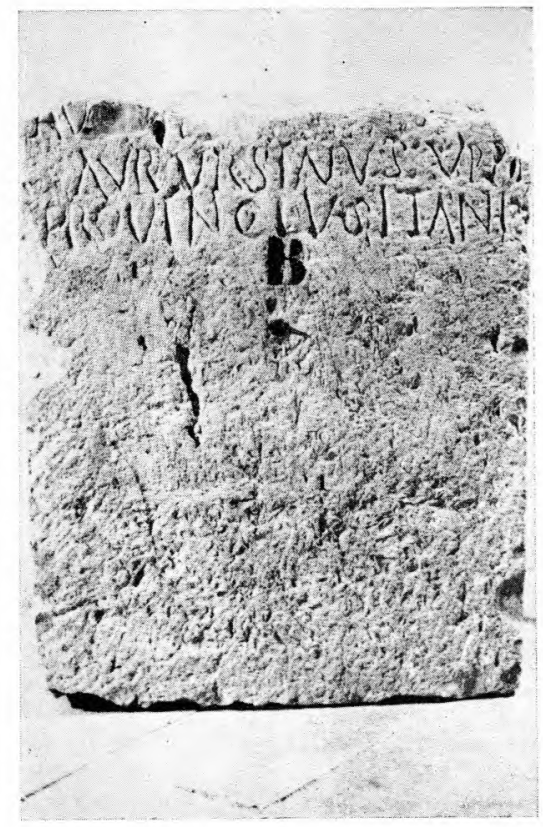




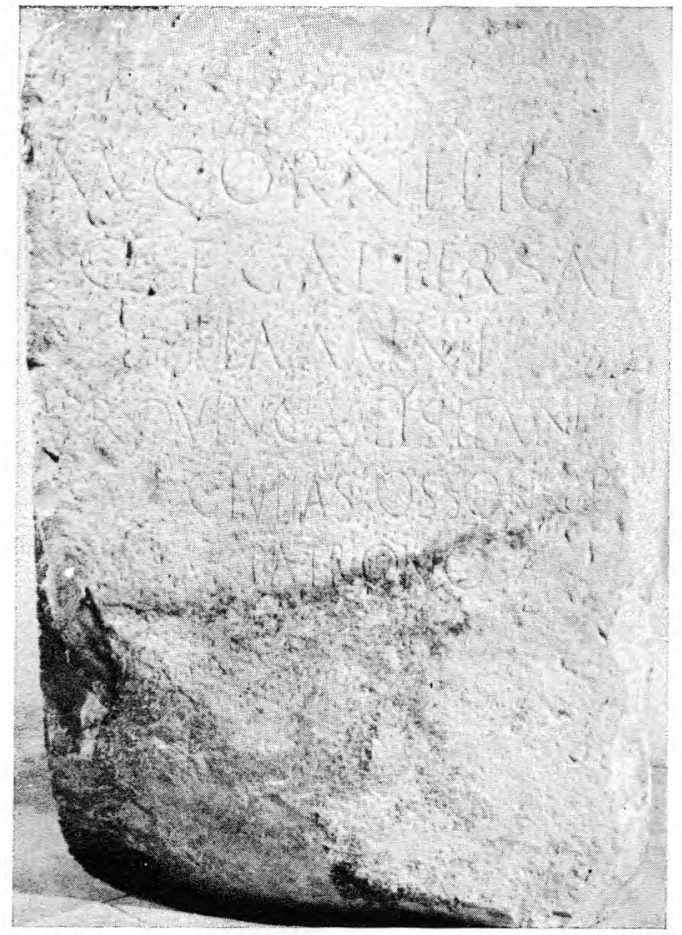



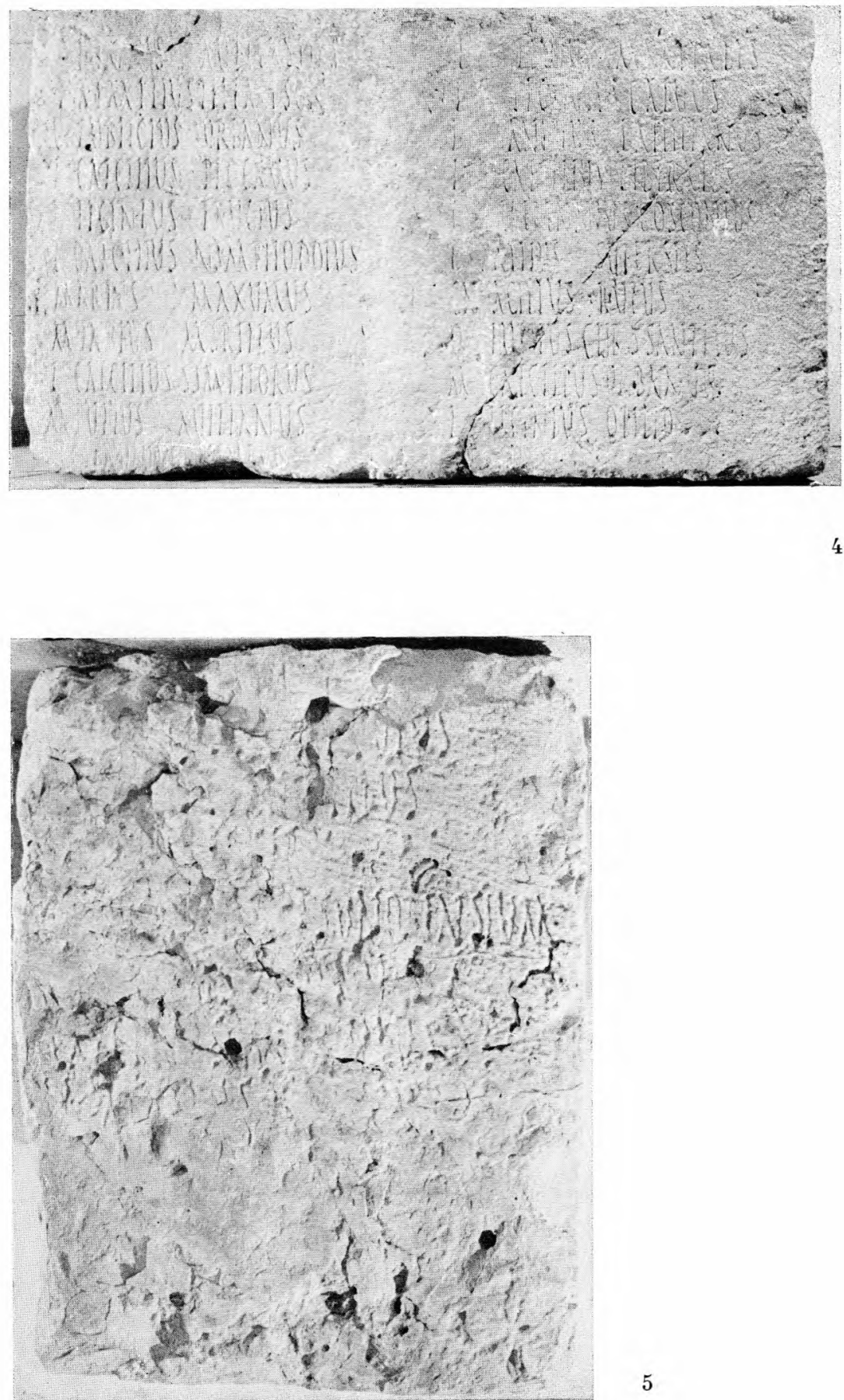


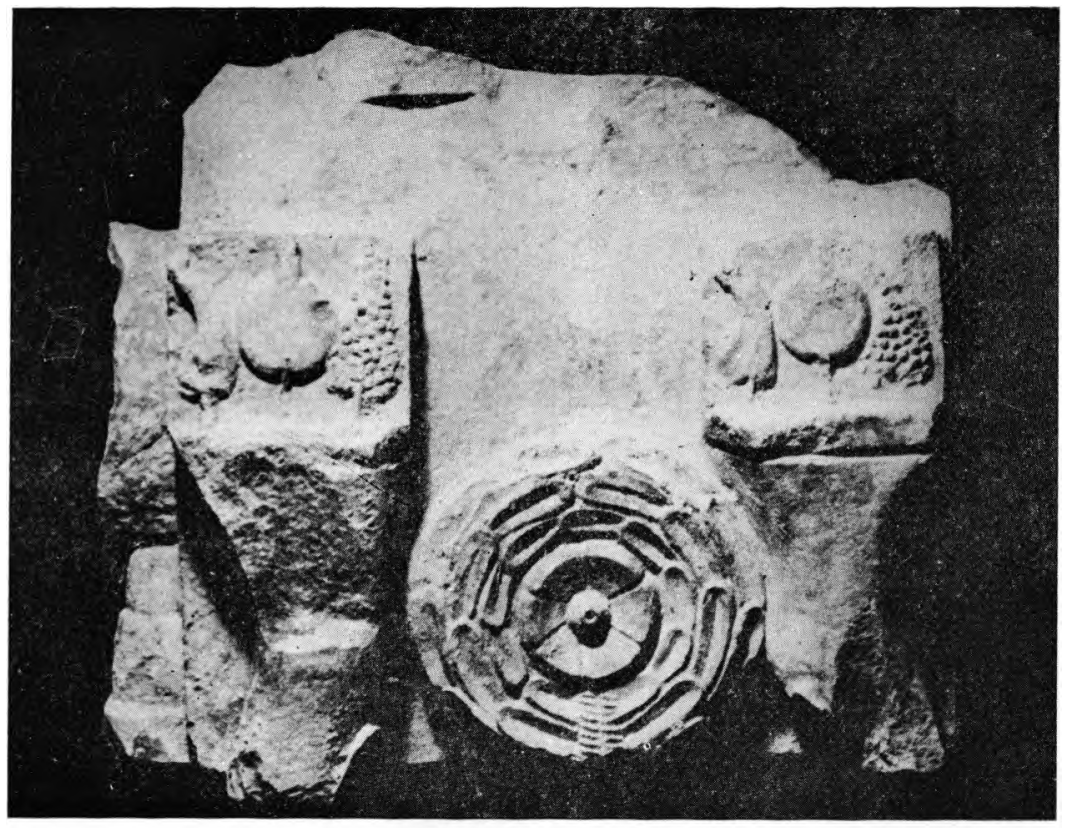

